\title{
Silicon Supplementation Alters the Composition of Herbivore Induced Plant Volatiles and Enhances Attraction of Parasitoids to Infested Rice Plants
}

\begin{abstract}
Jian Liu'1,2,3,4, Jiwei Zhu'1,2,3, Pengjun Zhang ${ }^{5}$, Liwei Han ${ }^{1,2,3}$, Olivia L. Reynolds 1,2,6, Rensen Zeng ${ }^{7}$, Jinhong Wu $u^{1,2,3}$, Yue Shao ${ }^{1,2,3}$, Minsheng You ${ }^{1,2,3}$ and Geoff M. Gurr ${ }^{1,2,3,4 *}$

${ }^{1}$ State Key Laboratory of Ecological Pest Control for Fujian and Taiwan Crops, Fujian Agriculture and Forestry University, Fuzhou, China, ${ }^{2}$ Institute of Applied Ecology, Fujian Agriculture and Forestry University, Fuzhou, China, ${ }^{3}$ Fujian-Taiwan Joint Innovation Centre for Ecological Control of Crop Pests, Fujian Agriculture and Forestry University, Fuzhou, China, ${ }^{4}$ Graham Centre for Agricultural Innovation, Charles Sturt University, Orange, NSW, Australia, ${ }^{5}$ Zhejiang Provincial Key Laboratory of Biometrology and Inspection and Quarantine, China Jiliang University, Hangzhou, China, ${ }^{6}$ Graham Centre for Agricultural Innovation, New South Wales Department of Primary Industries, Menangle, NSW, Australia, ${ }^{7}$ College of Crop Science, Fujian Agriculture and Forestry University, Fuzhou, China
\end{abstract}

Silicon (Si) is important in plant defenses that operate in a direct manner against herbivores, and work in rice (Oryza sativa) has established that this is mediated by the jasmonate signaling pathway. Plant defenses also operate indirectly, by the production of herbivore induced plant volatiles (HIPVs) that attract predators and parasitoids of herbivores. These indirect defenses too are mediated by the jasmonate pathway but no earlier work has demonstrated an effect of Si on HIPVs. In this study, we tested the effect of Si supplementation versus $\mathrm{Si}$ deprivation to rice plants on subsequent HIPV production following feeding by the important pest, rice leaffolder (Cnaphalocrocis medinalis). Gas chromatography-mass spectrometry analyses showed lower production of $\alpha$-bergamotene, $\beta$-sesquiohellandrene, hexanal 2-ethyl, and cedrol from + Si herbivore-infested plants compared with - Si infested plants. These changes in plant chemistry were ecologically significant in altering the extent to which parasitoids were attracted to infested plants. Adult females of Trathala flavo-orbitalis and Microplitis mediator both exhibited greater attraction to the HIPV blend of +Si plants infested with their respective insect hosts compared to -Si infested plants. In equivalent studies using RNAi rice plants in which jasmonate perception was silenced there was no equivalent change to the HIPV blend associated with Si treatment; indicating that the effects of $\mathrm{Si}$ on HIPVs are modulated by the jasmonate pathway. Further, this work demonstrates that silicon alters the HIPV blend of herbivore-infested rice plants. The significance of this finding is that there are no earlier-published studies of this phenomenon in rice or any other plant species. Si treatment to crops offers scope for enhancing induced, indirect defenses and associated biological control of pests because parasitoids are more strongly attracted by the HIPVs produced by +Si plants.

Keywords: HIPV, induced plant defense, biological control, jasmonate, hexanal 2-ethyl, $\alpha$-bergamotene, $\beta$-sesquiohellandrene, cedrol 


\section{INTRODUCTION}

Silicon ( $\mathrm{Si}$ ) has not historically been considered an essential plant nutrient though it has been termed 'quasi-essential' (Epstein, 1994; Luyckx et al., 2017). Evidence has mounted in the last decade that Si plays important roles in plant defense against biotic and abiotic stress (Ma et al., 2001; Ma, 2004; Ahmed et al., 2013; Balakhnina and Borkowska, 2013; Pontigo et al., 2015; Cooke and Leishman, 2016) including against insect herbivores and pathogens in agriculture (Ye et al., 2013; Wang et al., 2017). Among studies of the effects of Si on plant defense against herbivores, two primary modes of action have emerged as important. The first of these is the mechanical mode afforded by the deposition of inorganic amorphous oxide $\left(\mathrm{SiO}_{2}\right)$ phytoliths in the epidermis of foliage and in spines and trichomes (Ma, 2004; Hartley et al., 2015). These defenses are often constitutive ('always on') but can also be induced by damage such that the plant is responding to herbivory with greater deposition of silicon in defense structures (Hartley et al., 2015). Silicon deposition provides structural rigidity to plants and the resulting physical toughness also makes the plant surface less vulnerable to penetration and colonization by fungal pathogens (Wang et al., 2017) and tougher for herbivores to masticate and digest (Kvedaras and Keeping, 2007; Reynolds et al., 2016). The second mode of action of silicon in plant defense is enhancement of the induced production of defense chemicals ( $\mathrm{Wu}$ and Baldwin, 2010) including enzymes such as polyphenol oxidase and inhibitors such as trypsin protease inhibitor. For both of the foregoing mechanisms, there is strong evidence that the influence of $\mathrm{Si}$ is mediated by the jasmonate signaling pathway (Ye et al., 2013). The lipid-derived plant hormone, jasmonate, plays several important roles in plant metabolism including prioritization of defense over plant growth when a plant is under biotic stress (Yang et al., 2012). Ye et al. (2013) demonstrated Si elevated rice plant defense against rice leaffolder (Cnaphalocrocis medinalis) by promoting phytolith accumulation in leaves as well as polyphenol oxidase, peroxidase, trypsin protease inhibitor, and Bowman-Birk protease inhibitor activity. The significance of the jasmonate pathway in these effects was established by use of RNAi to silence expression of the CORONATINE INSENSITIVE1 gene which is involved in jasmonate perception. For the RNAi rice plants, the positive effects of $\mathrm{Si}$ on plant defenses were negated, leading to normal development of the herbivore. By logical extension, it is expected that the influence of $\mathrm{Si}$ on plant defense will also apply to mechanisms other than the two broad types described above, provided that these mechanisms too are mediated by the jasmonate pathway.

Plant defenses are not always direct in nature; they can also operate indirectly via the third trophic level, the natural enemies of herbivores. Work in recent decades has amply demonstrated that plants are able to manipulate the composition of the volatiles they emit, such that they serve as synomones, semiochemicals that benefit both the emitter and receiver (Becker et al., 2015). In this mechanism, a plant responds to herbivore attack by producing a particular herbivore induced plant volatiles (HIPVs) blend to which natural enemies such as predators and parasitoids are attracted, leading them to attack the herbivores (Mumm and Dicke, 2010; Schuman et al., 2012). Crucially, the jasmonate pathway is the most important of the three known signaltransduction pathways that underlie the induction of HIPVs (Ament et al., 2004; Wei et al., 2011; Zhang et al., 2013). Accordingly, the positive effects of $\mathrm{Si}$ on direct plant defenses described above may apply to indirect plant defense based on HIPV production.

To date, no work has been published on the effects of Si on HIPVs in any plant system. There is, however, indirect evidence that HIPVs may be affected by Si treatment to plants. Using a cucumber system, Kvedaras et al. (2010) demonstrated that Si enhanced the attraction of the predator, Dicranolaius bellulus, to plants infested by Helicoverpa armigera. An associated field study showed that Si-treated plants were more attractive to 'wild' predators than Si deficient control plants (Kvedaras et al., 2010). Whilst those results are consistent with Si altering the HIPV blend of pest-infested plants, that paper did not include any results for the volatiles emitted by the plants. This leads to the hypothesis that $\mathrm{Si}$ alters the HIPV blend thus enhancing the attraction of natural enemies. To test our hypothesis, we studied the volatiles of rice plants grown under Si deficient conditions versus with Si supplementation, and determined the effects on volatiles when infested by a major economic insect pest. We then complemented volatile studies with behavioral assays to determine whether attraction of biologically relevant parasitoid species was affected by changes in volatiles. Finally, RNAi plants were used to explore whether silenced perception affected the influence of the Si regime on plant volatiles.

\section{MATERIALS AND METHODS}

\section{Plants}

Rice plants of wild type (WT, var. Shishoubaimao) and a CORONATINE INSENSITIVE1 (OsCOI1) RNAi line deficient in jasmonate perception were used in this study. The OsCOI1 line was generated as described by Ye et al. (2013). Plants were hydroponically grown in climate control chambers $\left(27 \pm 1^{\circ} \mathrm{C}\right.$, $75 \pm 5 \% \mathrm{RH}$ ) using a modified Hoagland's solution (Hoagland and Arnon, 1950). For + Si rice plants, a hydroponic solution with $2.11 \mathrm{mM}$ sodium metasilicate $\left(\mathrm{Na}_{2} \mathrm{SiO}_{3}\right)$ was used. For $-\mathrm{Si}$ rice plants, $4.22 \mathrm{mM}$ of $\mathrm{Na}^{+}$was added to the hydroponic solution to equalize $\mathrm{Na}^{+}$concentrations with $+\mathrm{Si}$ rice plants. The $\mathrm{pH}$ of solutions was mediated to $5.6-6.0$ by adding hydrochloride acid. Hydroponic solution was renewed weekly and plants were grown to 6-8 weeks of age for all studies.

\section{Herbivores and Parasitoids}

Folded rice leaves with middle-aged to mature larvae of C. medinalis feeding inside were collected from the experimental farm of South China Agricultural University $\left(23^{\circ} 17^{\prime} \mathrm{N}\right.$, $\left.113^{\circ} 36^{\prime} \mathrm{E}\right)$. Foliage was kept turgid by immersing the cut ends in water within insect rearing cages $(45 \mathrm{~cm} \times 45 \mathrm{~cm} \times 45 \mathrm{~cm})$ placed in climate controlled rooms $\left(27 \pm 1^{\circ} \mathrm{C}, 75 \pm 5 \% \mathrm{RH}\right)$ to obtain adult $C$. medinalis. Newly emerged adults were transferred onto 2- to 3-week-old maize (Zea mays L.) plants to generate 
the larvae used in experiments. The rice leaffolder parasitoid, T. flavo-orbitalis, was reared from hosts collected from the experimental farm of Fujian Agriculture and Forestry University $\left(26^{\circ} 29^{\prime} \mathrm{N}, 118^{\circ} 48^{\prime} \mathrm{E}\right)$. Army worm (Mythimna separata (Walker)) and its parasitoid, Microplitis mediator Haliday, were supplied by Keyun Biocontrol (Henan, China) and Hebei Academy of Agricultural and Forestry Sciences (Hebei, China), respectively.

\section{Plant Volatile Analysis}

Rice volatile organic compounds were collected by dynamic headspace collection (Zhang et al., 2009). One rice plant was placed in a $15-\mathrm{L}$ glass vessel. Purified air was pumped into the vessel at $200 \mathrm{~mL} / \mathrm{min}$. The system was purged for $1 \mathrm{~h}$ before attaching a tube filled with $80 \mathrm{mg}$ matrix Porapak Q (Sigma-Aldrich) to the air outlet to adsorb the volatiles. Headspace collections were carried out at $27 \pm 1^{\circ} \mathrm{C}, 70 \pm 5 \% \mathrm{RH}$, and lasted for $4 \mathrm{~h}$. Samples were collected from plants in each of the following experimental treatments for WT and OsCOI1 rice: $+\mathrm{Si}+$ Herbivore; $+\mathrm{Si}-$ Herbivore; $-\mathrm{Si}+$ Herbivore; and $-\mathrm{Si}$ -Herbivore. All plant treatments were prepared concurrently with individual plants laid out in separate insect proof cages $(50 \mathrm{~cm} \times 50 \mathrm{~cm} \times 50 \mathrm{~cm})$. Volatile collection commenced $12 \mathrm{~h}$ after the plants were infested with four 3 rd instar larvae per plant. Each treatment had nine replicates.

Headspace samples were eluted by $500 \mu \mathrm{L}$ dichloromethane into 2 -mL glass vials, then mixed with $5 \mu \mathrm{L}$ internal standard nonyl acetate at $100 \mathrm{ng} / \mu \mathrm{L}$. Volatiles samples were then analyzed by GC-MS (Agilent 7890B-5977A). The temperature was held at $40^{\circ} \mathrm{C}$ for $3 \mathrm{~min}$ then increased at $5^{\circ} \mathrm{C} \mathrm{min}^{-1}$ to $220^{\circ} \mathrm{C}$. Compounds were identified by comparing the mass spectra with the instrument's internal NIST 2011 spectra database and Wiley Spectra Lab (John Wiley \& Sons, New York, NY, United States). The quantity of each compound was calculated by comparing the peak area of each compound with internal standard.

\section{Olfactometer Studies of Parasitoids on WT Rice Plants}

Two rice-herbivore-parasitoid systems were used: WT-C. medinalis-T. flavo-orbitalis and WT-M. separataM. mediator. To obtain herbivore attacked plants, four 3rd instar larvae of either herbivore species were allowed to feed on one plant for $12 \mathrm{~h}$. All larvae were then removed carefully without further mechanical damage to the plant before connecting to the Y-tube olfactometer. Pairs of plants were set up as: $-\mathrm{Si}$ + Herbivore vs. $-\mathrm{Si}$-Herbivore; $+\mathrm{Si}+$ Herbivore vs. $+\mathrm{Si}$ -Herbivore; and $-\mathrm{Si}+$ Herbivore vs. $+\mathrm{Si}+$ Herbivore. Each pair of plants was connected to the arms of a Y-tube olfactometer to test parasitoid response to treatments. Plants were placed individually into the volatile collection apparatus and purified air supplied at $100 \mathrm{~mL} / \mathrm{min}$. Preference responses of parasitic wasps to the pairs of plants described above were tested in a Y-tube olfactometer. Individual female adult wasps were released at the downwind side of the tube and 2 min were allowed for the wasp to pass the Y-tube junction and remain in that arm, otherwise the wasp was recorded as a no choice. Each odor comparison was repeated on 3-4 days with 10-20 wasps per day.

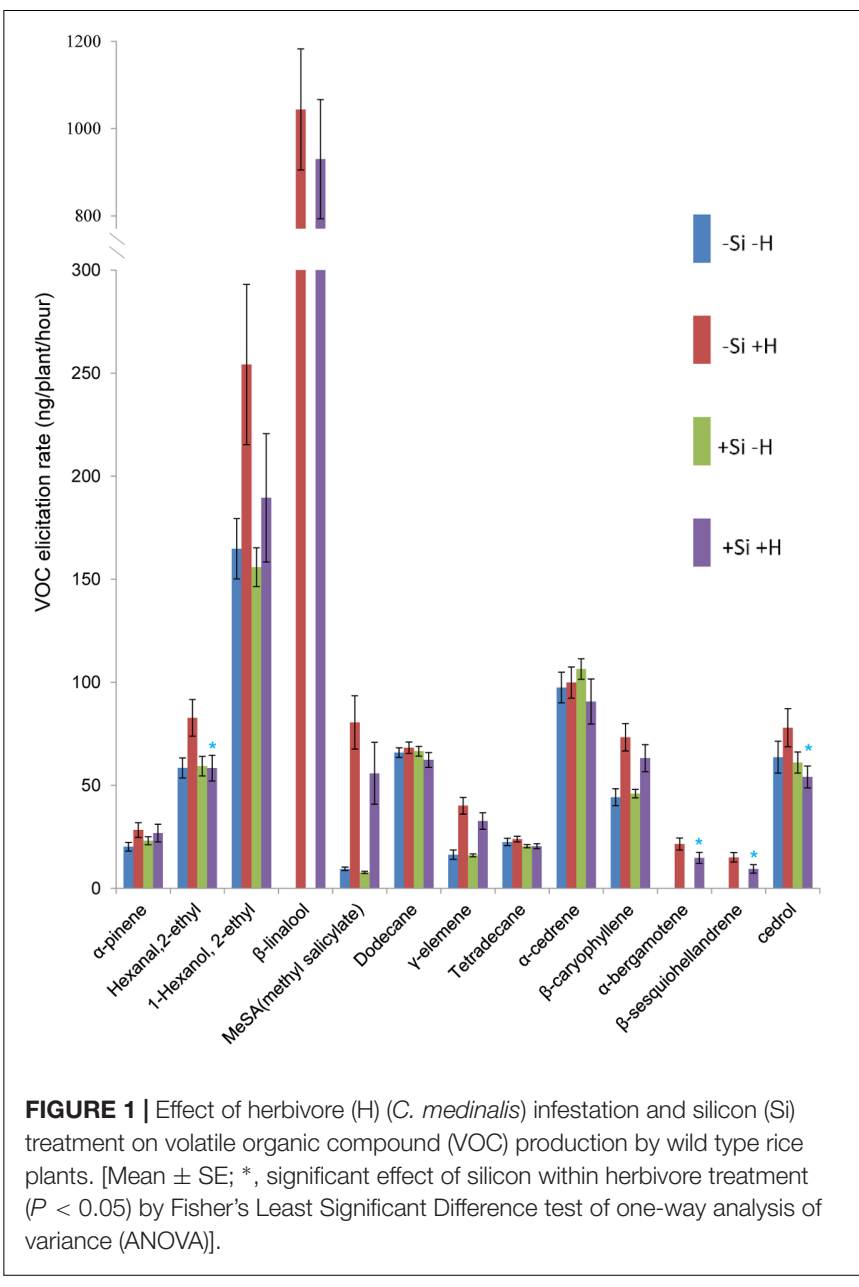

\section{Statistical Analysis}

Data analysis was undertaken using SPSS software (IBM SPSS Statistics version 24.0, Armonk, NY, United States). For plant volatile analysis, the average elicitation rate $(\mathrm{ng} / \mathrm{plant} / \mathrm{h})$ was calculated for each identified compound from nine replicates of each treatment (with exception of eight for treatment $+\mathrm{Si}+$ Herbivore). Fisher protected least significant difference (LSD) tests of analysis of variance (ANOVA) was used to compare the difference level between treatments.

Y-tube olfactometer data were analyzed using a Chi-square test. Wasps that did not make a choice were excluded from the analysis.

\section{RESULTS}

\section{Effect of Silicon on HIPVs}

Thirteen of 60 compounds were identified from the volatile blend collected as head space samples of rice plants. The composition of volatile blends was affected by $C$. medinalis infestation. For WT plants, $\beta$-linalool, $\alpha$-bergamotene, and $\beta$-sesquiohellandrene were detected only in samples from + Herbivore plants, whether + Si or $-\mathrm{Si}$ (Figures 1, 2). Production of five other compounds, 
hexanal 2-ethyl, 1-hexanol 2-ethyl, methyl salicylate (MeSA), $\gamma$-elemene, and $\beta$-caryophyllene, was significantly elevated ( $P$-value: $0.011,0.020,<0.001,<0.001,<0.001$, respectively) for $-\mathrm{Si}+$ Herbivore plants $(82,254,81,40,73 \mathrm{ng} / \mathrm{plant} / \mathrm{h}$, respectively) compared with $-\mathrm{Si}$-Herbivore plants (58, $164,10,16,44 \mathrm{ng} / \mathrm{plant} / \mathrm{h}$, respectively). Infested $+\mathrm{Si}$ plants produced significantly lower amounts (compared with $-\mathrm{Si}$ +Herbivore plants) of four compounds: hexanal 2-ethyl, $\alpha$-bergamotene, $\beta$-sesquiohellandrene and cedrol (Figure 1) (58, $15,9,54 \mathrm{ng} / \mathrm{plant} / \mathrm{h}$, respectively, vs. $83,22,15,78 \mathrm{ng} / \mathrm{plant} / \mathrm{h}$, respectively) ( $P$-value: $0.013,0.022,0.015,0.027$, respectively).

For OsCOI1 plants, as in WT plants, $\beta$-linalool, $\alpha$-bergamotene, and $\beta$-sesquiohellandrene were detected only in samples from + Herbivore plants, whether $+\mathrm{Si}$ or $-\mathrm{Si}$ (Figure 2). Production of MeSA, $\gamma$-elemene, and $\beta$-caryophyllene was significantly ( $P$-value: $0.030,0.016,0.020$, respectively) elevated for +Herbivore plants compared with -Herbivore plants (-Si + Herbivore: 54, 27, $59 \mathrm{ng} /$ plant/h, respectively, vs. $-\mathrm{Si}$ -Herbivore: 7, 14, $40 \mathrm{ng} /$ plant/h, respectively; $+\mathrm{Si}+$ Herbivore: 68, 37, $71 \mathrm{ng} / \mathrm{plant} / \mathrm{h}$, respectively, vs. $+\mathrm{Si}-$ Herbivore: 3,16 , $44 \mathrm{ng} /$ plant/h, respectively) (Figure 2). However, the effect of $\mathrm{Si}$ on OsCOI1 plants differed from that observed for WT plants. Infested + Si plants produced higher (rather than lower) amounts of $\alpha$-bergamotene and $\beta$-sesquiohellandrene compared with $-\mathrm{Si}+$ Herbivore plants $(18,14 \mathrm{ng} / \mathrm{plant} / \mathrm{h}$, respectively, vs. 10 , $7 \mathrm{ng} / \mathrm{plant} / \mathrm{h}$, respectively) ( $P$-value: $0.034,0.034$, respectively); whilst production of hexanal 2-ethyl and cedrol was unaffected by $\mathrm{Si}$ treatment (rather than being suppressed by $\mathrm{Si}$ as observed in WT plants).

\section{Parasitoid Response to HIPVs}

The responses of both parasitoids T. flavo-orbitalis and M. mediator to experimental treatments was consistent across species. The volatile blend of + Herbivore plants was significantly more attractive than the blend from -Herbivore plants, regardless of Si regime (Figures 3, 4). Both parasitoids also responded significantly more strongly to the volatile blend of $+\mathrm{Si}$ + Herbivore than to $-\mathrm{Si}+$ Herbivore plants.

\section{DISCUSSION}

Silicon is the second most abundant element in the earth's crust, yet the vast majority of this is not available to plants (Epstein, 1994; Savant et al., 1997; Ma and Yamaji, 2006), existing predominantly as feldspars and quartz minerals. Plants take up $\mathrm{Si}$ from the soil solution as silicic acid $\left[\mathrm{Si}(\mathrm{OH})_{4}\right]$, or $\mathrm{Si}(\mathrm{OH})_{3} \mathrm{O}^{-}$ at high $\mathrm{pH}$, so although the $\mathrm{Si}$ content of soils can be as high as 45\% (Currie and Perry, 2007), availability can be low. Deficiencies are especially important for plants such as rice that require this element in large amounts (Horuz et al., 2013). Evidence of this is the fact that plants have evolved influx, efflux and channeltype transporters to actively uptake Si (Ma and Yamaji, 2006, 2015; Trembath-Reichert et al., 2015; Vivancos et al., 2016) as well as that yield increases when plant-available $\mathrm{Si}$ is added to the growing medium (Tavakkoli et al., 2011). The beneficial roles of Si to various plants have been the subject of extensive

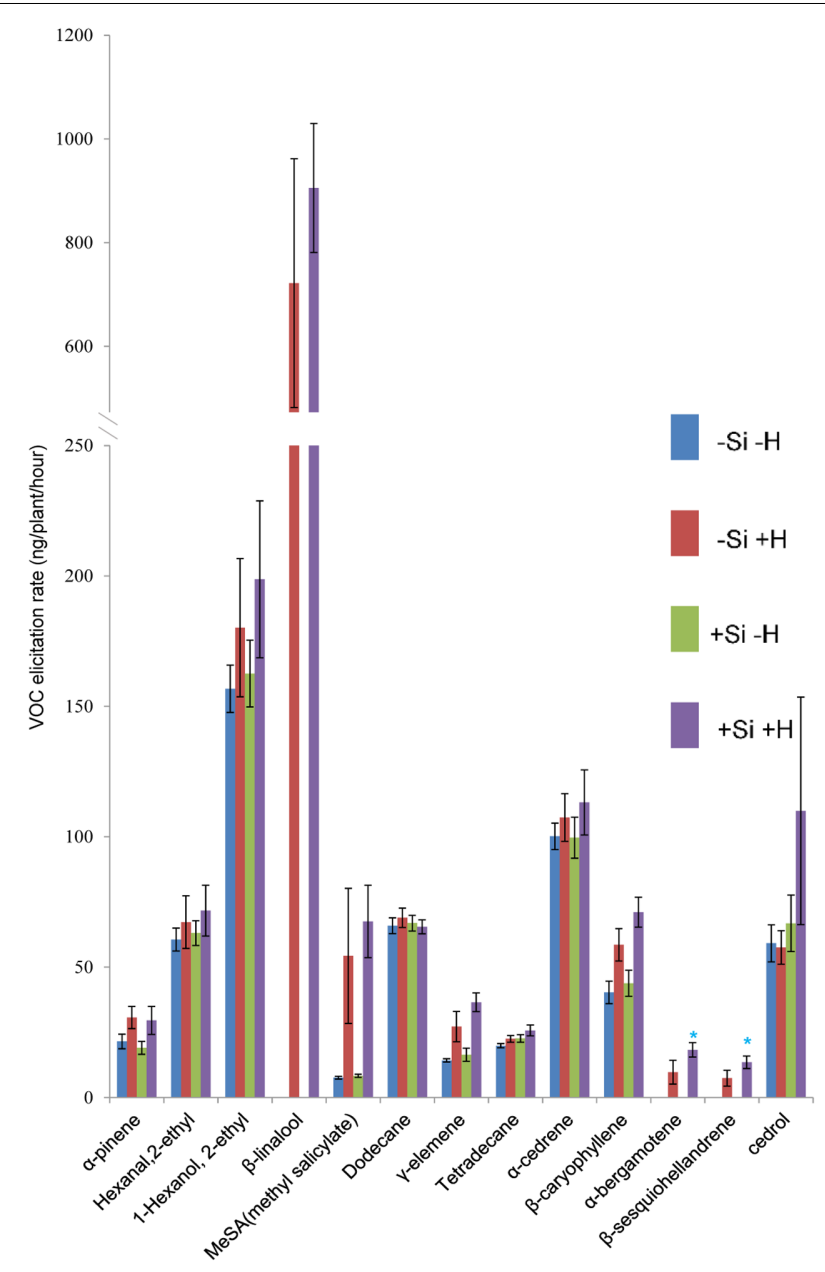

FIGURE 2 | Effect of herbivore $(\mathrm{H})$ (C. medinalis) infestation and silicon (Si) treatment on volatile organic compound (VOC) production by OsCO/1 RNAi rice plants. [Mean $\pm \mathrm{SE}$; ${ }^{*}$, significant effect of silicon within herbivore treatment $(P<0.05)$ by Fisher's Least Significant Difference test of one-way analysis of variance (ANOVA)].

research and include alleviation of abiotic stresses such as drought (Marques et al., 2016), metal toxicity, and micronutrient deficiency (Hernandez-Apaolaza, 2014); and biotic stress from pathogens (Winslow, 1992; Vivancos et al., 2015) and herbivores (Reynolds et al., 2009, 2016; Ye et al., 2013). To date, there is increasing evidence of $\mathrm{Si}$ priming plants for defense against herbivore attack (Reynolds et al., 2009; Hartley and DeGabriel, 2016). But, a conspicuous gap in knowledge about the effects of Si on plant biology is for the volatiles that are produced by plants and that are often key semiochemicals that drive ecological interactions including induced, indirect plant defense against herbivores enemies (Pare and Tumlinson, 1999; Dicke and Loon, 2000; Degenhardt et al., 2003).

The present results support our hypothesis and show, for the first time in any plant species, that plants grown with available Si have a different HIPV profile compared to plants grown under Si deficiency. Earlier work by Kvedaras et al. (2010) showed that 

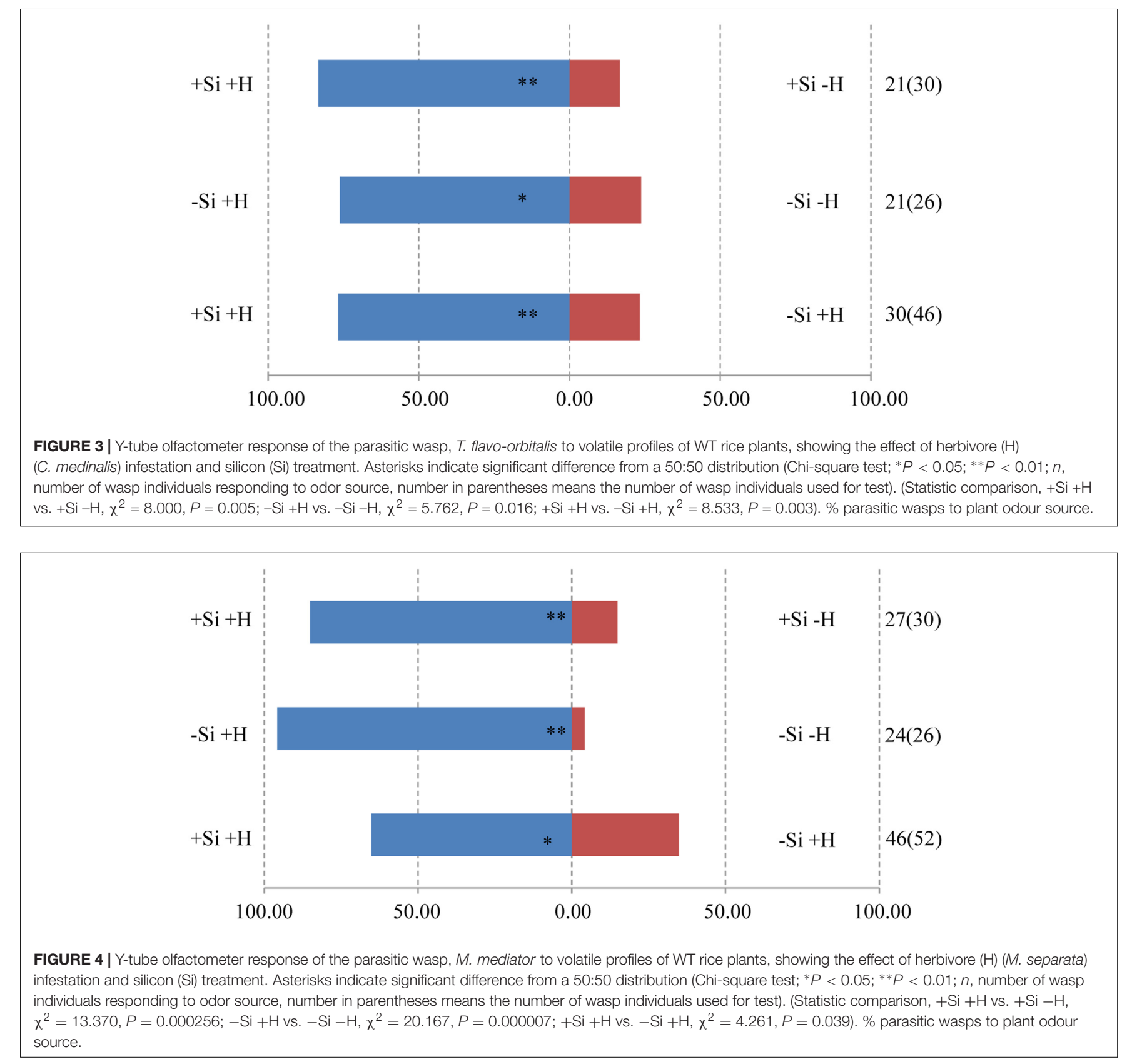

+ Si plants were more attractive than - Si plants to a generalist predator in olfactometer tests and to wild predators (of unknown identity) in a field experiment. That study did not, however, include work on plant volatiles so the mechanism underpinning the apparent effects on predators remained unclear. In the present study, several of the volatile compounds that were influenced by herbivore infested rice plants were shown to be HIPVs, since they were not produced by uninfested plants, irrespective of the $\mathrm{Si}$ status of the plant. These were $\beta$-linalool, $\alpha$-bergamotene, and $\beta$-sesquiohellandrene, each of which have been identified as HIPVs in other studies (Hare, 2011; De Backer et al., 2016; PintoZevallos et al., 2016). Whilst it is possible to record antennal responses for parasitoids to individual HIPVs (Takemoto and
Takabayashi, 2015), it is known that blends of HIPVs and the relative quantity of different compounds is more important than any single compound (Van Wijk et al., 2010, 2011). Accordingly, in addition to the three compounds that were produced only by infested plants, several others were produced in greater quantities by infested rather than healthy plants: hexanal 2-ethyl, 1-hexanol 2 -ethyl, methyl salicylate, $\gamma$-elemene and $\beta$-caryophyllene. Most crucially, the differences in blends between plants with a different $\mathrm{Si}$ regime (within herbivore treatment) involved a significant change in the composition of volatiles produced, with lower production of two of the HIPVs ( $\alpha$-bergamotene and $\beta$-sesquiohellandrene) and of hexanal 2-ethyl and cedrol. Hexanal 2-ethyl (synonym, 2-ethyl hexanol) has been reported as 
a volatile compound released by Rutaceae spp. foliage (Robbins et al., 2012) and is produced by insect-damaged roots of carrot (Daucus carota) (Weissteiner and Schütz, 2006). Cedrol has been reported as a foliar and fruit volatile produced by Ficus carica L. (Soltana et al., 2017) and, though it has not been reported to be a HIPV, exhibits bioactivity against arthropod pests (Eller et al., 2014).

The foregoing differences in volatile blends between experimental treatments were demonstrated to have ecological relevance by the behavior of two parasitoid wasp species. Both $T$. flavo-orbitalis and $M$. mediator responded more strongly to the volatile blend from + Herbivore plants than - Herbivore plants within each of the $\mathrm{Si}$ regimes, demonstrating that the experimental conditions were suitable for these parasitoids to exhibit biologically appropriate behavior consistent with HIPVs guiding them to infested plants. Crucially, both parasitoids also exhibited a significant preference to the odor blend from $+\mathrm{Si}$ over -Si when both of these treatments were herbivore-infested.

The nature of the change in volatile blend brought about by Si pre-treatment (Figures 1, 2) was not a clear cut switching-on, or -off, for the release of a given compound. Rather, the results are consistent with earlier studies showing that it is the ratio of compounds in blends that is crucial for attraction to natural enemies (Pare and Tumlinson, 1999; Dicke and Loon, 2000; Degenhardt et al., 2003). Specifically, our results are consistent with the heuristic that both parasitoids were attracted to a blend (Figures 3, 4) in which the major HIPVs, especially linalool, were present but in which more minor volatiles (hexanal-2-ethyl and cedrol) were at background levels, equivalent to those emitted by herbivore-free plants.

The present study establishes a stronger evidence base for exploring scope to promote biological control of pest herbivores by ensuring that crops have an optimal supply of Si so that they are able to mount a strong induced, indirect defense based on HIPV production. Fully exploiting the apparent priming effects of Si on plant defense demands a more comprehensive understanding of the underlying metabolic pathways. Work by Ye et al. (2013) demonstrated the importance of the jasmonate signaling pathway for positive effects of $\mathrm{Si}$ on rice defenses. The present study demonstrates that $\mathrm{Si}$ can enhance the attractiveness of the HIPV blends produced by WT rice when attacked by

\section{REFERENCES}

Ahmed, M., Kamran, A., Asif, M., Qadeer, U., Ahmed, Z. I., and Goyal, A. (2013). Silicon priming: a potential source to impart abiotic stress tolerance in wheat: a review. Aust. J. Crop Sci. 7:484.

Ament, K., Kant, M. R., Sabelis, M. W., Haring, M. A., and Schuurink, R. C. (2004). Jasmonic acid is a key regulator of spider mite-induced volatile terpenoid and methyl salicylate emission in tomato. Plant Physiol. 135, 2025-2037. doi: 10.1104/pp.104.048694

Balakhnina, T., and Borkowska, A. (2013). Effects of silicon on plant resistance to environmental stresses: review. Int. Agrophys. 27, 225-232. doi: 10.2478/ v10247-012-0089-4

Becker, C., Desneux, N., Monticelli, L., Fernandez, X., Michel, T., and Lavoir, A. V. (2015). Effects of abiotic factors on hipv-mediated interactions between plants and parasitoids. Biomed. Res. Int. 2015:342982. doi: 10.1155/2015/ 342982 a herbivore but that this effect of Si does not occur among RNAi plants with silenced jasmonate perception. The emission of HIPVs is known to be influenced by the jasmonate pathway, particularly in the case of chewing herbivores such as those used in the present study (Dicke and Baldwin, 2010). Accordingly, the present results support the finding of Ye et al. (2013) that Si promotes plant defenses via the jasmonate pathway, but extends the range of effects to include HIPVs production. Further studies are required to determine whether $\mathrm{Si}$ also interacts with the salicylic acid and ethylene defense pathways of plants (Ruther and Kleier, 2005; Zarate et al., 2007; Koornneef et al., 2008; Dicke et al., 2009). Each of these, as well as the jasmonate pathway, can lead to the induction of HIPVs including by feeding of sucking pests such as aphids (Ozawa et al., 2000; van Poecke and Dicke, 2002). It will, therefore, be important to determine the extent of interactions between $\mathrm{Si}$ and varying plant defense mechanisms in order to fully exploit the potential of this element in novel plant protection approaches.

\section{AUTHOR CONTRIBUTIONS}

JL and GG designed the experiments. JL, JZ, LH, JW, and YS conducted the experiment. JL, PZ, and GG analyzed and interpreted the data. JL, OR, MY, and GG drafted and revised the paper. All authors read and approved the final manuscript.

\section{FUNDING}

This work was supported by the Thousand Talents Fellowship (KX1452102) of China awarded to GG and National Natural Science Foundation of China (31471779) to PZ. OR is supported by the Jinshan Scholar Fellowship at Fujian Agriculture and Forestry University.

\section{ACKNOWLEDGMENTS}

We thank Pingyang Zhu, Qiang Li, Huan Liu, Lilin Chen, Jianyu $\mathrm{Li}$, and Ying Xiao for collecting rice leaffolder in the field.

Cooke, J., and Leishman, M. R. (2016). Consistent alleviation of abiotic stress with silicon addition: a meta-analysis. Funct. Ecol. 30, 1340-1357. doi: 10.1111/13652435.12713

Currie, H. A., and Perry, C. C. (2007). Silica in plants: biological, biochemical and chemical studies. Ann. Bot. 100, 1383-1389. doi: 10.1093/aob/mcm247

De Backer, L., Bawin, T., Schott, M., Gillard, L., Markó, I. E., Francis, F., et al. (2016). Betraying its presence: identification of the chemical signal released by Tuta absoluta-infested tomato plants that guide generalist predators toward their prey. Arthropod-Plant Inte 11, 111-120. doi: 10.1007/s11829-016-9471-7

Degenhardt, J., Gershenzon, J., Baldwin, I. T., and Kessler, A. (2003). Attracting friends to feast on foes: engineering terpene emission to make crop plants more attractive to herbivore enemies. Curr. Opin. Biotechnol. 14, 169-176. doi: 10.1016/S0958-1669(03)00025-9

Dicke, M., and Baldwin, I. T. (2010). The evolutionary context for herbivoreinduced plant volatiles: beyond the 'cry for help'. Trends Plant Sci. 15, 167-175. doi: 10.1016/j.tplants.2009.12.002 
Dicke, M., and Loon, J. J. (2000). Multitrophic effects of herbivore-induced plant volatiles in an evolutionary context. Entomol. Exp. Appl. 97, 237-249. doi: 10.1046/j.1570-7458.2000.00736.x

Dicke, M., van Loon, J. J., and Soler, R. (2009). Chemical complexity of volatiles from plants induced by multiple attack. Nat. Chem. Biol. 5, 317-324. doi: $10.1038 /$ nchembio. 169

Eller, F. J., Vander Meer, R. K., Behle, R. W., Flor-Weiler, L. B., and Palmquist, D. E. (2014). Bioactivity of cedarwood oil and cedrol against arthropod pests. Environ. Entomol. 43, 762-766. doi: 10.1603/EN13270

Epstein, E. (1994). The anomaly of silicon in plant biology. Proc. Natl. Acad. Sci. U.S.A. 91, 11-17. doi: 10.1073/pnas.91.1.11

Hare, J. D. (2011). Ecological role of volatiles produced by plants in response to damage by herbivorous insects. Annu. Rev. Entomol. 56, 161-180. doi: 10.1146/ annurev-ento-120709-144753

Hartley, S. E., and DeGabriel, J. L. (2016). The ecology of herbivore-induced silicon defences in grasses. Funct. Ecol. 30, 1311-1322. doi: 10.1111/1365-2435.12706

Hartley, S. E., Fitt, R. N., McLarnon, E. L., and Wade, R. N. (2015). Defending the leaf surface: intra- and inter-specific differences in silicon deposition in grasses in response to damage and silicon supply. Front. Plant Sci. 6:35. doi: $10.3389 /$ fpls.2015.00035

Hernandez-Apaolaza, L. (2014). Can silicon partially alleviate micronutrient deficiency in plants? A review. Planta 240, 447-458. doi: 10.1007/s00425-0142119-x

Hoagland, D. R., and Arnon, D. I. (1950). The water-culture method for growing plants without soil. Circular. Calif. Agric. Exp. Stat. 347:32.

Horuz, A., Korkmaz, A., and Karaman, M. R. (2013). Response of paddy soils to silicon fertilization. Tarim Bilim Derg 19, 268-280. doi: 10.1007/s00253-0157131-y

Koornneef, A., Leon-Reyes, A., Ritsema, T., Verhage, A., Den Otter, F. C., Van Loon, L. C., et al. (2008). Kinetics of salicylate-mediated suppression of jasmonate signaling reveal a role for redox modulation. Plant Physiol. 147, 1358-1368. doi: 10.1104/pp.108.121392

Kvedaras, O. L., An, M., Choi, Y. S., and Gurr, G. M. (2010). Silicon enhances natural enemy attraction and biological control through induced plant defences. Bull. Entomol. Res. 100, 367-371. doi: 10.1017/S0007485309990265

Kvedaras, O. L., and Keeping, M. G. (2007). Silicon impedes stalk penetration by the borer Eldana saccharina in sugarcane. Entomol. Exp. Appl. 125, 103-110. doi: 10.1111/j.1570-7458.2007.00604.x

Luyckx, M., Hausman, J. F., Lutts, S., and Guerriero, G. (2017). Silicon and plants: current knowledge and technological perspectives. Front. Plant Sci. 8:411. doi: 10.3389/fpls.2017.00411

Ma, J., Miyake, Y., and Takahashi, E. (2001). Silicon as a beneficial element for crop plants. Stud. Plan S 8, 17-39. doi: 10.1016/S0928-3420(01)80006-9

Ma, J. F. (2004). Role of silicon in enhancing the resistance of plants to biotic and abiotic stresses. Soil Sci. Plant Nutr. 50, 11-18. doi: 10.1080/00380768.2004. 10408447

Ma, J. F., and Yamaji, N. (2006). Silicon uptake and accumulation in higher plants. Trends Plant Sci. 11, 392-397. doi: 10.1016/j.tplants.2006.06.007

Ma, J. F., and Yamaji, N. (2015). A cooperative system of silicon transport in plants. Trends Plant Sci. 20, 435-442. doi: 10.1016/j.tplants.2015.04.007

Marques, D. J., Ferreira, M. M., Lobato, A. K. D., de Freitas, W. A., Carvalho, J. D., Ferreira, E. D., et al. (2016). Potential of calcium silicate to mitigate water deficiency in maize. Bragantia 75, 275-285. doi: 10.1590/1678-4499.446

Mumm, R., and Dicke, M. (2010). Variation in natural plant products and the attraction of bodyguards involved in indirect plant defense. Can. J. Zool. 88, 628-667. doi: 10.1139/Z10-032

Ozawa, R., Arimura, G., Takabayashi, J., Shimoda, T., and Nishioka, T. (2000). Involvement of jasmonate- and salicylate-related signaling pathways for the production of specific herbivore-induced volatiles in plants. Plant Cell Physiol. 41, 391-398. doi: 10.1093/pcp/41.4.391

Pare, P. W., and Tumlinson, J. H. (1999). Plant volatiles as a defense against insect herbivores. Plant Physiol. 121, 325-331. doi: 10.1104/pp.121.2.325

Pinto-Zevallos, D. M., Strapasson, P., and Zarbin, P. H. G. (2016). Herbivoreinduced volatile organic compounds emitted by maize: electrophysiological responses in Spodoptera frugiperda females. Phytochem. Lett. 16, 70-74. doi: 10.1016/j.phytol.2016.03.005

Pontigo, S., Ribera, A., Gianfreda, L., de la Luz Mora, M., Nikolic, M., and Cartes, P. (2015). Silicon in vascular plants: uptake, transport and its influence on mineral stress under acidic conditions. Planta 242, 23-37. doi: 10.1007/s00425-0152333- 1

Reynolds, O. L., Keeping, M. J., and Meyer, J. (2009). Silicon-augmented resistance of plants to herbivorous insects: a review. Ann. Appl. Biol. 155, 171-176. doi: 10.1111/j.1744-7348.2009.00348.x

Reynolds, O. L., Padula, M. P., Zeng, R., and Gurr, G. M. (2016). Silicon: potential to promote direct and indirect effects on plant defense against arthropod pests in agriculture. Front. Plant Sci. 7:744. doi: 10.3389/fpls.2016.00744

Robbins, P. S., Alessandro, R. T., Stelinski, L. L., and Lapointe, S. L. (2012). Volatile profiles of young leaves of Rutaceae spp. varying in susceptibility to the asian citrus psyllid (Hemiptera: Psyllidae). Fla Entomol. 95, 774-776. doi: 10.1653/ 024.095.0331

Ruther, J., and Kleier, S. (2005). Plant-plant signaling: ethylene synergizes volatile emission in Zea mays induced by exposure to (Z)-3-hexen-1-ol. J. Chem. Ecol. 31, 2217-2222. doi: 10.1007/s10886-005-6413-8

Savant, N. K., Datnoff, L. E., and Snyder, G. H. (1997). Depletion of plant-available silicon in soils: a possible cause of declining rice yields. Commun. Soil Sci. Plan 28, 1245-1252. doi: 10.1080/00103629709369870

Schuman, M. C., Barthel, K., and Baldwin, I. T. (2012). Herbivory-induced volatiles function as defenses increasing fitness of the native plant Nicotiana attenuata in nature. Elife 1:e00007. doi: 10.7554/eLife.00007

Soltana, H., Flamini, G., and Hammami, M. (2017). Volatile compounds from six varieties of Ficus carica from Tunisia. Rec. Nat. Prod. 11, 157-165.

Takemoto, H., and Takabayashi, J. (2015). Parasitic wasps Aphidius ervi are more attracted to a blend of host-induced plant volatiles than to the independent compounds. J. Chem. Ecol. 41, 801-807. doi: 10.1007/s10886-0150615-5

Tavakkoli, E., Lyons, G., English, P., and Guppy, C. N. (2011). Silicon nutrition of rice is affected by soil $\mathrm{pH}$, weathering and silicon fertilisation. J. Plant Nutr. Soil Sci. 174, 437-446. doi: 10.1002/jpln.201000023

Trembath-Reichert, E., Wilson, J. P., McGlynn, S. E., and Fischer, W. W. (2015). Four hundred million years of silica biomineralization in land plants. Proc. Natl. Acad. Sci. U.S.A. 112, 5449-5454. doi: 10.1073/pnas.1500289112

van Poecke, R. M., and Dicke, M. (2002). Induced parasitoid attraction by Arabidopsis thaliana: involvement of the octadecanoid and the salicylic acid pathway. J. Exp. Bot. 53, 1793-1799. doi: 10.1093/jxb/erf022

Van Wijk, M., De Bruijn, P. J., and Sabelis, M. W. (2010). The predatory mite Phytoseiulus persimilis does not perceive odor mixtures as strictly elemental objects. J. Chem. Ecol. 36, 1211-1225. doi: 10.1007/s10886-010-9858-3

Van Wijk, M., De Bruijn, P. J., and Sabelis, M. W. (2011). Complex odor from plants under attack: herbivore's enemies react to the whole, not its parts. PLoS ONE 6:e21742. doi: 10.1371/journal.pone.0021742

Vivancos, J., Deshmukh, R., Gregoire, C., Remus-Borel, W., Belzile, F., and Belanger, R. R. (2016). Identification and characterization of silicon efflux transporters in horsetail (Equisetum arvense). J. Plant Physiol. 200, 82-89. doi: 10.1016/j.jplph.2016.06.011

Vivancos, J., Labbé, C., Menzies, J. G., and Bélanger, R. R. (2015). Silicon-mediated resistance of Arabidopsis against powdery mildew involves mechanisms other than the salicylic acid (SA)-dependent defence pathway. Mol. Plant Pathol. 16, 572-582. doi: 10.1111/mpp.12213

Wang, M., Gao, L., Dong, S., Sun, Y., Shen, Q., and Guo, S. (2017). Role of silicon on plant-pathogen interactions. Front. Plant Sci. 8:701. doi: 10.3389/fpls.2017. 00701

Wei, J., Wang, L., Zhao, J., Li, C., Ge, F., and Kang, L. (2011). Ecological tradeoffs between jasmonic acid-dependent direct and indirect plant defences in tritrophic interactions. New Phytol. 189, 557-567. doi: 10.1111/j.1469-8137. 2010.03491.x

Weissteiner, S., and Schütz, S. (2006). Are different volatile pattern influencing host plant choice of belowground living insects. Mitt. Dtsch. Ges. Allg. Angew Ent. 15, 51-55.

Winslow, M. D. (1992). Silicon, disease resistance, and yield of rice genotypes under upland cultural conditions. Crop Sci. 32, 1208-1213. doi: 10.2135/cropsci1992. 0011183X003200050030x

Wu, J., and Baldwin, I. T. (2010). New insights into plant responses to the attack from insect herbivores. Annu. Rev. Genet 44, 1-24. doi: 10.1146/annurev-genet102209-163500

Yang, D. L., Yao, J., Mei, C. S., Tong, X. H., Zeng, L. J., Li, Q., et al. (2012). Plant hormone jasmonate prioritizes defense over growth by interfering with 
gibberellin signaling cascade. Proc. Natl. Acad. Sci. U.S.A. 109, E1192-E1200. doi: 10.1073/pnas.1201616109

Ye, M., Song, Y., Long, J., Wang, R., Baerson, S. R., Pan, Z., et al. (2013). Priming of jasmonate-mediated antiherbivore defense responses in rice by silicon. Proc. Natl. Acad. Sci. U.S.A. 110, E3631-E3639. doi: 10.1073/pnas.13058 48110

Zarate, S. I., Kempema, L. A., and Walling, L. L. (2007). Silverleaf whitefly induces salicylic acid defenses and suppresses effectual jasmonic acid defenses. Plant Physiol. 143, 866-875. doi: 10.1104/pp.106.090035

Zhang, P. J., Broekgaarden, C., Zheng, S. J., Snoeren, T. A., van Loon, J. J., Gols, R., et al. (2013). Jasmonate and ethylene signaling mediate whiteflyinduced interference with indirect plant defense in Arabidopsis thaliana. New Phytol. 197, 1291-1299. doi: 10.1111/nph.12106

Zhang, P. J., Zheng, S. J., van Loon, J. J., Boland, W., David, A., Mumm, R., et al. (2009). Whiteflies interfere with indirect plant defense against spider mites in Lima bean. Proc. Natl. Acad. Sci. U.S.A. 106, 21202-21207. doi: 10.1073/pnas. 0907890106
Conflict of Interest Statement: GG and OR hold research funding from Australian Steel Mill Services (a potential source of silicacious material) and this supports a project being conducted independently of the present work. Australian Steel Mill Services had no role in the present study, interpretation of results or decision to publish.

The other authors declare that the research was conducted in the absence of any commercial or financial relationships that could be construed as a potential conflict of interest.

Copyright $\odot 2017$ Liu, Zhu, Zhang, Han, Reynolds, Zeng, Wu, Shao, You and Gurr. This is an open-access article distributed under the terms of the Creative Commons Attribution License (CC BY). The use, distribution or reproduction in other forums is permitted, provided the original author(s) or licensor are credited and that the original publication in this journal is cited, in accordance with accepted academic practice. No use, distribution or reproduction is permitted which does not comply with these terms. 